\title{
New Anticoagulants for Atrial Fibrillation
}

\author{
Magdalena Sobieraj-Teague, M.B.B.S., ${ }^{1}$ Martin O'Donnell, M.B., ${ }^{1}$ \\ and John Eikelboom, M.B.B.S. ${ }^{1}$
}

\begin{abstract}
Atrial fibrillation is already the most common clinically significant cardiac arrhythmia and a common cause of stroke. Vitamin $\mathrm{K}$ antagonists are very effective for the prevention of cardioembolic stroke but have numerous limitations that limit their uptake in eligible patients with AF and reduce their effectiveness in treated patients. Multiple new anticoagulants are under development as potential replacements for vitamin $\mathrm{K}$ antagonists. Most are small synthetic molecules that target factor IIa (e.g., dabigatran etexilate, AZD-0837) or factor Xa (e.g., rivaroxaban, apixaban, betrixaban, DU176b, idrabiotaparinux). These drugs have minimal protein binding and predictable pharmacokinetics that allow fixed dosing without laboratory monitoring and are being compared with vitamin $\mathrm{K}$ antagonists or aspirin in phase III clinical trials. A new vitamin $\mathrm{K}$ antagonist (ATI-5923) with improved pharmacological properties compared with warfarin is also being evaluated in a phase III trial. None of the new agents have as yet been approved for clinical use.
\end{abstract}

KEYWORDS: Atrial fibrillation, anticoagulants, stroke, factor Xa inhibitor, direct thrombin inhibitor

Atrial fibrillation (AF) is the most common clinically significant cardiac arrhythmia. The prevalence of $\mathrm{AF}$ increases with age, approaching $10 \%$ in those $>80$ years. ${ }^{1}$ Because of progressive aging of the population, the worldwide burden of AF is expected to increase dramatically over the next 50 years. ${ }^{1,2}$ The major clinical significance of $\mathrm{AF}$ lies in the increased risk of stroke and systemic embolism. ${ }^{3,4}$ Compared with ischemic stroke due to other causes, strokes associated with AF tend to be more severe and are associated with a higher mortality, greater disability, and higher health-care costs. ${ }^{5-7}$

Currently, approved antithrombotic strategies for management of patients with $\mathrm{AF}$ include vitamin $\mathrm{K}$ antagonists (VKAs) (e.g., warfarin, acenocoumarol, phenprocoumon) and antiplatelet agents, most commonly aspirin. VKAs reduce the risk of stroke by 60 to $70 \%$ compared with placebo and by $40 \%$ compared with aspirin, ${ }^{3,8,9}$ and they are recommended for patients at a moderate to high risk of stroke, which accounts for $>70 \%$ of patients with $\mathrm{AF}^{10}$ Aspirin offers only a modest protection against cardioembolic stroke, reducing the risk by $\sim 20 \%$ compared with placebo. ${ }^{11}$

Despite their established efficacy, VKAs have limitations that reduce their uptake and limit their effectiveness (Table 1). VKAs have a slow onset and offset of action, a narrow therapeutic window, and a metabolism that is affected by diet, drugs, and genetic polymorphisms. Because of their variable dose-response and unpredictable anticoagulant effect, frequent laboratory monitoring and dose adjustments are necessary to ensure therapy is safe and efficacious. The requirement for international normalized ratio (INR) monitoring is inconvenient and costly for patients and health-care systems.

${ }^{1}$ McMaster University, Hamilton, Ontario, Canada.

Address for correspondence and reprint requests: Dr. Magdalena Sobieraj-Teague, Hamilton General Hospital, Level 7, Room 714, 237 Barton Street East, Hamilton, Ontario, L8L 2X2 Canada (e-mail: teaguem@mcmaster.ca).

Arterial Thrombosis; Guest Editors, Pieter W. Kamphuisen,

M.D., Ph.D., Frits R. Rosendaal, M.D., Ph.D., and Harry R. Büller, M.D., Ph.D.

Semin Thromb Hemost 2009;35:515-524. Copyright (C) 2009 by Thieme Medical Publishers, Inc., 333 Seventh Avenue, New York, NY 10001, USA. Tel: $+1(212)$ 584-4662.

DOI 10.1055/s-0029-1234147. ISSN 0094-6176. 


\section{Table 1 Limitations of Vitamin K Antagonists}

- Slow onset and offset of action

- Narrow therapeutic index

- Variable and unpredictable anticoagulant effect due to

$>$ Genetic polymorphisms of CYP2C9* and $\mathrm{VKORC} 1^{\dagger}$ genes

$>$ Multiple food and drug interactions

$>$ Concurrent disease

- Need for monitoring of anticoagulant effect and dose adjustments

*Cytochrome P450 (CYP2C9).

†itamin K epoxide reductase complex subunit 1 (VKORC1).

To a large extent, it is the limitations of VKAs that explain why only about half of eligible patients actually receive VKA therapy. ${ }^{10,12-17}$ Of those who receive VKA treatment, the INR is outside the recommended therapeutic range for 30 to $50 \%$ of the time. ${ }^{12,16-20}$ Reduced time in therapeutic range is associated with poorer outcomes, including an increased risk of ischemic stroke, higher rate of hospitalization, and increased risk of death. ${ }^{18,21,22}$

The limitations of VKAs have prompted the search for new, more effective, safer, and more convenient anticoagulant alternatives for use in AF. This article focuses on new anticoagulants that are currently under evaluation for use in patients with $\mathrm{AF}$ with emphasis on agents that have been, or are likely to be, introduced into clinical practice in the near future.

\section{NEW ANTICOAGULANTS}

Table 2 lists the characteristics of an ideal anticoagulant. Although the main focus of anticoagulant drug development has been on new oral agents to replace VKAs, a novel long-acting parental agent is also being studied. The new anticoagulants are all small synthetic molecules with advantages that include minimal protein binding, predictable pharmacokinetics, and fixed dosing without the need for laboratory monitoring. The main research focus for stroke prevention in AF has been with specific inhibitors of factor $\mathrm{Xa}$ and factor IIa (thrombin). Inhibitors of $\mathrm{Xa}$ prevent thrombin generation either by directly binding to factor $\mathrm{Xa}$ (e.g., rivaroxaban, apixaban, betrixaban, DU176b) or indirectly catalyzing antithrombin inhibition of $\mathrm{Xa}$ (e.g., idraparinux, idrabiotaparinux). Oral thrombin inhibitors (e.g., dabigatran etexilate, AZD-0837) bind directly to thrombin, preventing conversion of fibrinogen to fibrin. Direct inhibitors of Xa and IIa act even when these factors are bound to fibrin or prothrombinase, meaning that these agents may have an advantage in preventing thrombus progression. ATI5923 is a structural analog of warfarin that has improved pharmacological properties due to its small molecular size and esterase pathway metabolism. Table 3 summarizes the pharmacological characteristics of the new anticoagulants.

\section{ORAL THROMBIN INHIBITORS IN PHASE III TRIALS}

\section{Dabigatran Etexilate}

\section{PHARMACOLOGY}

Dabigatran etexilate, a direct thrombin inhibitor, is an oral prodrug of the active moiety dabigatran, which binds reversibly to both clot-bound and fluid-phase thrombin inhibiting thrombus formation and thrombin-induced platelet activation. ${ }^{23}$ It has a rapid onset of action of 1 to 2 hours and a half-life of 12 to 17 hours. The bioavailability of dabigatran etexilate is $\sim 7 \%{ }^{24-26}$ Dabigatran does not induce or inhibit cytochrome p450 (CYP), has a predictable anticoagulant response, and it has a low potential for food or drug interactions, obviating the need for laboratory monitoring. ${ }^{24,25}$ It is predominantly renally cleared, and a reduced dose is recommended in patients with creatinine clearance between 30 and $50 \mathrm{~mL} /$ minute. Clinical studies have excluded patients with creatinine clearance $<30 \mathrm{~mL} /$ minute. There is no evidence that dabigatran causes liver injury, unlike its predecessor ximelagatran, the now withdrawn oral direct thrombin inhibitor.

Table 2 Characteristics of an Ideal Anticoagulant

\begin{tabular}{ll}
\hline Desired Characteristic & Practical Advantage \\
\hline Rapid onset of action & No need for overlap with heparin \\
Wide therapeutic index & Increased safety \\
Minimal side effects & Improved compliance; less monitoring \\
Oral formulation & Convenient administration \\
Predictable anticoagulant response & Fixed-dose unmonitored treatment \\
No food or drug interaction & No need for monitoring \\
Availability of antidote & Able to reverse in case of bleeding or urgent surgery \\
Cost effective & Accessibility \\
\hline
\end{tabular}




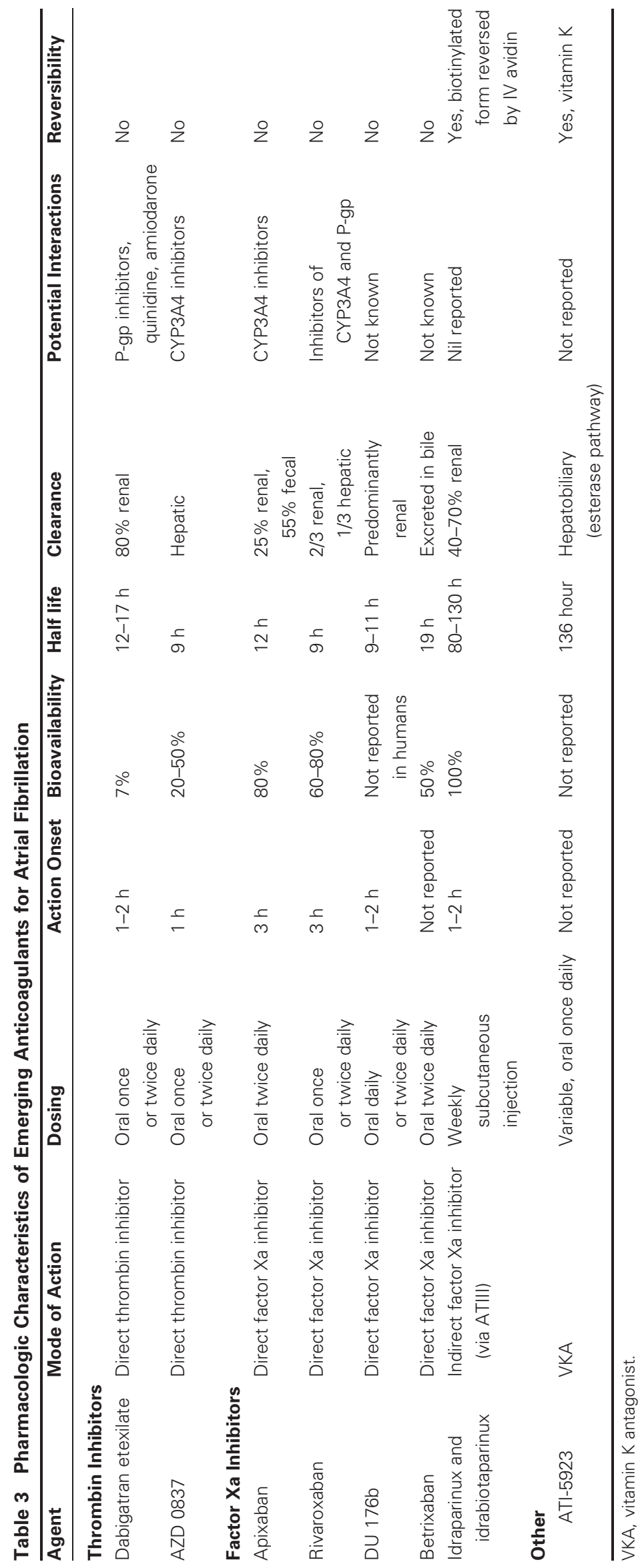




\section{CLINICAL EVALUATION}

On the basis of three large trials in venous thromboembolism (VTE) prevention in orthopedic surgery, ${ }^{27-29}$ dabigatran etexilate is approved in Europe, the United Kingdom, and Canada for prevention of VTE following hip and knee replacement surgery. The dosage used in these trials was dabigatran etexilate, 150 or $220 \mathrm{mg}$, once daily.

One phase II trial (Prevention of Embolic and Thrombotic Events in Patients with Persistent Atrial Fibrillation $[\mathrm{PETRO}]^{30}$ has evaluated dabigatran etexilate in AF. The main objective of this study was to determine the dose-related incidence of bleeding to guide dose selection for the subsequent phase III trial. The 502 patients were randomized to receive blinded doses of $50 \mathrm{mg}, 150 \mathrm{mg}$, or $300 \mathrm{mg}$ of dabigatran etexilate twice daily, alone or in combination with $81 \mathrm{mg}$ or $325 \mathrm{mg}$ of aspirin or open-label warfarin for 12 weeks. Of the patients assigned to dabigatran etexilate, the treatment was withdrawn in $7 \%$ due to adverse events. A further $3 \%$ had their assigned dose halved because of renal impairment. Concomitant aspirin was stopped in the $300 \mathrm{mg}$ dabigatran etexilate group following four episodes of major hemorrhage (this is the only group in which major bleeding was observed). Two episodes of stroke were reported, both in the dabigatran etexilate $50 \mathrm{mg}$ twice-daily group. Based on the results of PETRO, a $150 \mathrm{mg}$ twice-daily dose as well as a slightly lower $110 \mathrm{mg}$ twice-daily dose was chosen for further evaluation in the phase III trial.

An extended follow-up of participants in PETRO to assess the long-term effects of dabigatran on liver function is ongoing (PETRO-Ex). A large phase III randomized controlled trial (Randomized Evaluation of Long-Term Anticoagulant Therapy [RE-LY]), which completed recruitment of more than 18,000 participants, will determine whether long-term anticoagulation with dabigatran etexilate $(110 \mathrm{mg}$ or $150 \mathrm{mg}$ twice daily) is noninferior to open-label warfarin in patients with AF. Final study results are expected in 2009. The RELYABLE trial (Long-Term Multi-Center Extension of Dabigatran Treatment in Patients with Atrial Fibrillation Who Completed RE-LY Trial) is an extension of the RE-LY trial, which began in December 2008 and aims to evaluate longer term safety of dabigatran etexilate in 8000 patients.

\section{ORAL FACTOR XA INHIBITORS IN PHASE III TRIALS}

\section{Rivaroxaban}

\section{PHARMACOLOGY}

Rivaroxaban is an oral direct factor Xa inhibitor. It has high oral bioavailability (60 to $80 \%$ ) and rapid onset of action (3 hours). ${ }^{31}$ Rivaroxaban is excreted via two major routes: Two thirds is renally cleared, and a third is cleared via the fecal/biliary route. Approximately a third of the dose is excreted unchanged in the urine. ${ }^{32}$ The half-life in healthy young subjects is 5 to 9 hours and increases to 11 to 13 hours in the elderly as a result of decreased renal excretion. ${ }^{31}$ Caution is recommended in patients with moderate renal impairment (creatinine clearance [ $\mathrm{CrCl}$ ], 30 to $49 \mathrm{~mL} /$ minute), and rivaroxaban is contraindicated in severe renal impairment or severe liver disease. CYP3A4 and P-gp-inhibitors (e.g., ketoconazole, voriconazole, and ritonavir) reduce the metabolism of rivaroxaban, ${ }^{33}$ and their concomitant use in patients treated with rivaroxaban is contraindicated. Rivaroxaban has a predictable anticoagulant response negating the need for monitoring.

\section{CLINICAL EVALUATION}

Following four large trials of VTE prevention in orthopedic surgery, ${ }^{34-37}$ rivaroxaban, given at a dose of $10 \mathrm{mg}$ once daily, was approved in Europe and Canada for the prevention of VTE in patients undergoing hip and knee replacement surgery.

Two phase III trials in AF are currently underway. ROCKET-AF is a randomized, double-blind, international, noninferiority trial comparing the efficacy and safety of $20 \mathrm{mg}$ once-daily rivaroxaban to warfarin for prevention of stroke and systemic embolism. This study will enroll 14,000 subjects, and results are expected in 2010. The second study is a randomized, double-blind trial comparing a lower dose of rivaroxaban $(15 \mathrm{mg}$ once daily or $10 \mathrm{mg}$ once daily for $\mathrm{CrCl} 30-49 \mathrm{~mL} /$ minute) daily to warfarin in 1200 subjects with AF in Japan. Recruitment began in 2007, and results are expected in 2009.

\section{Apixaban}

\section{PHARMACOLOGY}

Apixaban is an oral, selective, direct factor $\mathrm{Xa}$ inhibitor. Apixaban is rapidly absorbed, reaching peak plasma concentration 3 hours postingestion. It has a bioavailability of $>50 \%$ and a half-life of 12 hours in healthy young volunteers. ${ }^{38}$ Apixaban has multiple elimination pathways, of which $\sim 25 \%$ is renal and $55 \%$ fecal. ${ }^{33}$ Cytochrome P450 3A4 and sulfotransferase 1A1 appear to be the major enzymes involved in the metabolism of apixaban. ${ }^{39}$ Apixaban has a low potential for drug or food interactions, but potent inhibitors of CYP 3A4 (e.g., clarithromycin, ketoconazole) increase drug concentrations and may be contraindicated. ${ }^{33}$

\section{CLINICAL EVALUATION}

The dose of apixaban being evaluated in AF was selected based on the results of phase II dose ranging studies in VTE prevention and treatment. ${ }^{40,41}$ 
A phase IIb, randomized, multicenter, partially blind (open-label warfarin) study is currently underway in Japan and is evaluating safety and efficacy of two doses of apixaban (2.5 and $5 \mathrm{mg}$ twice daily) in $250 \mathrm{AF}$ subjects. This study will conclude in 2009 .

Two phase III trials evaluating the efficacy and safety of apixaban in AF have been initiated. ARISTOTLE is a randomized, double-blind, noninferiority trial comparing the efficacy and safety of apixaban $5 \mathrm{mg}$ twice daily to warfarin for prevention of stroke and systemic embolism in patients with $\mathrm{AF}$ and at least one other risk factor for stroke. This trial aims to enroll 15,000 subjects, and results are expected in 2010. AVERROES is a randomized, double-blind, superiority trial that compares apixaban, $5 \mathrm{mg}$ twice daily or $2.5 \mathrm{mg}$ twice daily, in those deemed to be at high risk for bleeding (meeting at least two of the following criteria: age $\geq 80$ years, weight $\leq 60 \mathrm{~kg}$, creatinine $\geq 133 \mu \mathrm{mol} / \mathrm{L}$ ) to aspirin (81 to $324 \mathrm{mg}$ ) in patients with $\mathrm{AF}$ and at least one additional risk factor for stroke who are unsuitable or unwilling to receive VKA therapy. A total of 5,600 subjects will be enrolled, and results are expected in 2010.

\section{DU 176b}

\section{PHARMACOLOGY}

DU $176 \mathrm{~b}$ is an oral, direct factor $\mathrm{Xa}$ inhibitor. DU $176 \mathrm{~b}$ is rapidly absorbed, reaching peak plasma concentration 2 hours postingestion, has a half-life of 9 to 11 hours, and is predominantly excreted via the kidneys. $^{42}$

\section{CLINICAL EVALUATION}

A phase II, randomized, double-blind multicenter study (NCT00504556) in 2000 patients with AF and a $\mathrm{CHADS}_{2}$ (congestive heart failure, hypertension, age $>75$ years, diabetes, and prior stroke or transient ischemic attack [TIA]) score $\geq 2$ has been initiated. The trial is evaluating the safety of four fixed-dose regiments of DU-176b (30 and $60 \mathrm{mg}$ daily, and 30 and $60 \mathrm{mg}$ twice daily) as compared with warfarin over a 3-month period. A second phase II study (NCT00806624) is a randomized, doubleblinded study evaluating the safety of two unspecified fixed dosages of DU-176b versus open-label warfarin over a 3 -months treatment period in 235 subjects with $\mathrm{AF}$ with a $\mathrm{CHADS}_{2}$ score of $\geq 1$.

Engage-AF is a phase III, randomized, doubleblind study assessing safety and efficacy of two different dose regimens of DU-176b (high and low dose) versus warfarin in subjects with $\mathrm{AF}$ and a $\mathrm{CHADS}_{2}$ score $\geq 2$ (NCT00781391). The expected duration of the study is 24 months, and results are expected in 2011.

\section{PARENTERAL ANTICOAGULANTS IN PHASE III TRIALS}

\section{Idraparinux and Idrabiotaparinux}

\section{PHARMACOLOGY}

Idraparinux is a subcutaneously administered indirect inhibitor of factor $\mathrm{Xa}$. It has a rapid onset of action ( 2 hours) and a long half-life of 80 to 130 hours allowing once-weekly dosing. ${ }^{43,44}$ It has $100 \%$ bioavailability following subcutaneous injection and a predictable anticoagulant response negating the need for monitoring of anticoagulant effect. It is excreted unchanged via the kidneys, and caution is needed in patients with renal impairment.

Idrabiotaparinux (biotinylated idraparinux) is structurally identical to idraparinux with the addition of a biotin group. The pharmacodynamic and pharmacokinetic properties of idrabiotaparinux are similar to those of idraparinux..$^{45}$ However, unlike idraparinux, the anticoagulant activity of idrabiotaparinux can be rapidly reversed by the intravenous infusion of its antidote, Avidin, which in a clinical trial was effective in reversing the anticoagulant effect and well tolerated. ${ }^{46}$

\section{CLINICAL EVALUATION}

Idraparinux was shown to be effective compared with standard therapy (unfractionated heparin or low molecular weight heparin, followed by a VKA) for the treatment of deep vein thrombosis (DVT) in a large phase III study but was inferior to standard treatment when evaluated for the treatment of pulmonary embolism (PE). ${ }^{47}$ A recently completed phase III bioequivalence study in 700 patients demonstrated that idrabiotaparinux was as effective as idraparinux for the treatment of DVT but was associated with a lower rate of major bleeding. ${ }^{46}$

AMADEUS, a phase III randomized trial, compared the efficacy and safety of weekly fixed dose idraparinux with warfarin in 4576 patients with $\mathrm{AF}$ at moderate to high risk for stroke. Idraparinux was as effective as warfarin $(0.9 \%$ versus $1.3 \% ; p<0.01)$ but had a higher risk of clinically relevant bleeding $(19.7 \%$ versus $11.3 \% ; p<0.0001)$ with no difference in overall mortality. ${ }^{48}$ The trial was terminated early because of the increase in major bleeding. A multicenter, randomized, double-blind, noninferiority trial (BOREALIS-AF) is currently being conducted to compare idrabiotaparinux with warfarin in 9,600 patients with $\mathrm{AF}$ and $\mathrm{CHADS}_{2}$ score of $\geq 2$. Results are expected in early 2011 .

\section{OTHER EMERGING ANTICOAGULANTS FOR TREATMENT OF ATRIAL FIBRILLATION}

ATI-5923 is a novel warfarin analogue with improved pharmacological properties. It is a selective, 


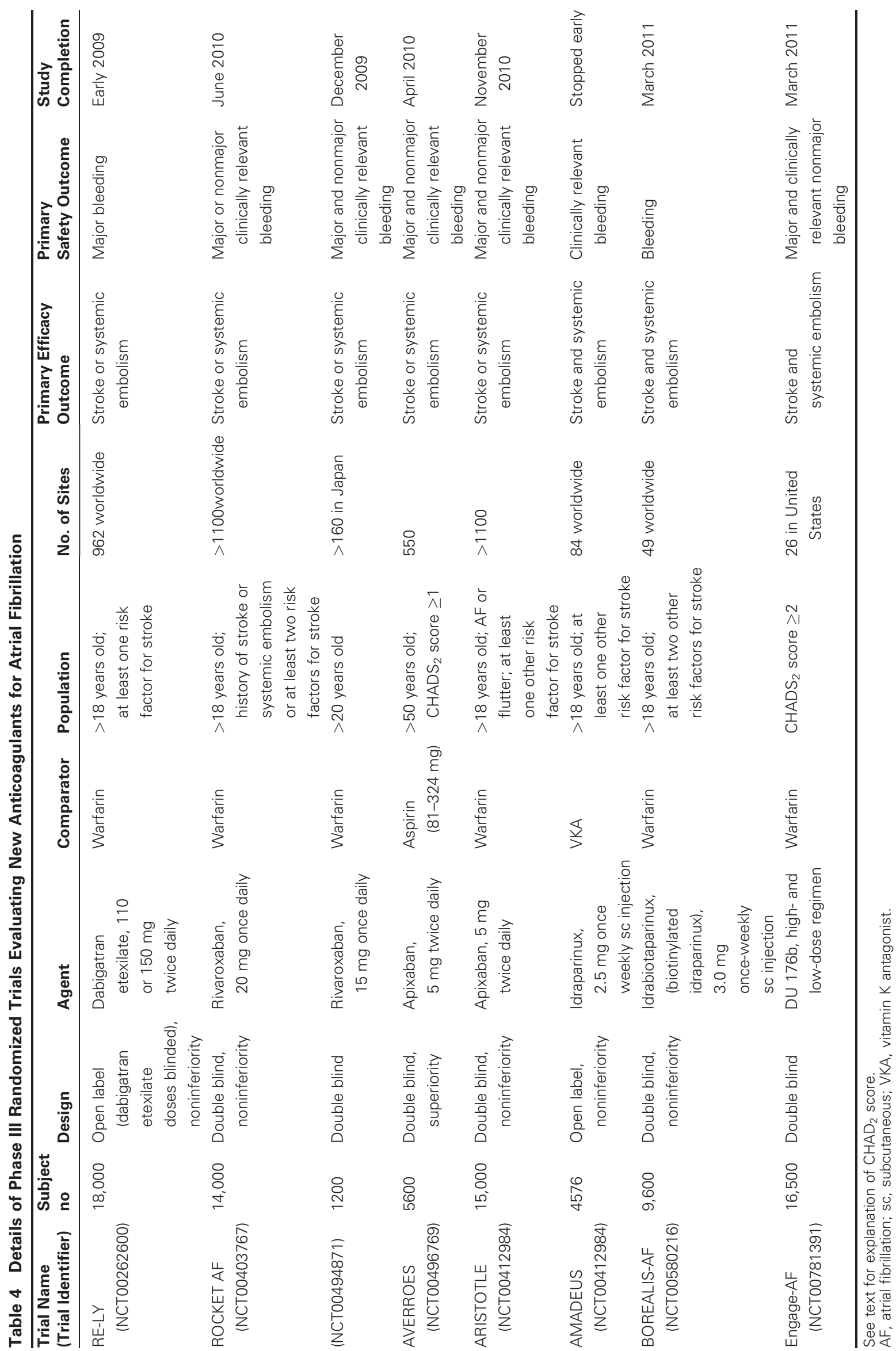


noncompetitive inhibitor of vitamin $\mathrm{K}$ epoxide reductase, but it is metabolized through the esterase pathway rather then the cytochrome $\mathrm{P} 450$ pathway. Consequently, ATI-5923 is expected to have less variable metabolism, fewer drug and food interactions, and a more predictable anticoagulant effect than warfarin. It has a half-life of 136 hours and 100\% hepatobiliary clearance. In a recent multicenter, phase II, open-label study of 66 patients with AF treated with ATI-5923 or warfarin, the mean time in therapeutic range was 71.5 and $59.3 \%$ for ATI-5923- and warfarin-treated patients, respectively, over 3 months $(p=0.0009){ }^{49}$

EmbraceAC is a phase II/III multicenter, randomized, stratified, double-blind, parallel group trial evaluating ATI-5923 versus warfarin in patients who require long-term anticoagulation including patients with $\mathrm{AF}$, atrial flutter, prosthetic heart valves, VTE, or a history of myocardial infarction or cardiomyopathy. The goal of this 600-subject study is to assess whether ATI-5923 is superior to warfarin at maintaining INR values within the therapeutic range. The study will conclude in 2009.

\section{AZD 0837}

AZD-0837 is a potent oral inhibitor of thrombin being developed as a replacement for ximelagatran, which was effective for prevention of stroke in patients with $\mathrm{AF}$ but was withdrawn because of liver toxicity. To date, limited preclinical data have been presented but not published. AZD-0837 is rapidly acting, reaching peak concentration within 1.5 hours postingestion, has bioavailability of 20 to $55 \%$, and a half-life of 9 hours. ${ }^{33}$ It is cleared via the liver.

Three phase II trials are underway evaluating AZD-0837 in patients with AF. NCT00684307 study is a phase II trial assessing the safety and tolerability of four different dosing regimens of AZD-0837 $(450 \mathrm{mg}$, $200 \mathrm{mg}, 300 \mathrm{mg}$, and $150 \mathrm{mg}$ ) compared with warfarin in 1084 patients with $\mathrm{AF}$ and one or more additional risk factors for stroke. Study enrollment was completed in mid-2008. NCT00623779 study is a phase II, randomized, open-label trial assessing the safety and tolerability of AZD-0837 for up to 3 months in 150 patients with AF who are unable or unwilling to take warfarin. Study enrollment concluded in December 2008. NCT00645853 study is a phase II, nonrandomized, open-label trial evaluating safety and tolerability of long-term (5 years) AZD-0837 treatment compared with warfarin in $>500 \mathrm{AF}$ patients at moderate to high risk of stroke. This study has completed enrollment.

\section{Betrixaban}

Betrixaban is an oral factor Xa inhibitor in early stages of clinical development. Betrixaban has an oral bioavail- ability of 50\%, a relatively long half-life of 19 hours, and is predominantly excreted unchanged in bile with minimal renal excretion. It has a low potential for drug-drug interactions. ${ }^{33}$

EXPLORE Xa, a phase II, randomized, double-blind, multicenter trial has been initiated evaluating safety, tolerability, and pilot efficacy of three blinded doses of betrixaban (40,60, and $80 \mathrm{mg}$ once daily compared with open-label warfarin in $500 \mathrm{pa}^{-}$ tients with $\mathrm{AF}$ who will be treated for at least 3 months.

\section{YM 150}

YM 150 is another oral direct factor Xa inhibitor in early stages of clinical development. To date, limited data have been presented but not published. A phase II randomized, double-blind dose-finding study (NCT00448214) assessing the safety and tolerability of YM 150 in comparison to open-label warfarin in subjects with $\mathrm{AF}$ completed recruitment in December 2008.

\section{CURRENT STATUS OF ANTICOAGULANT THERAPY FOR ATRIAL FIBRILLATION}

VKAs are effective for the prevention of stroke and systemic embolism in patients with $\mathrm{AF}$ and are presently the gold standard against which new anticoagulants are being compared. There is substantial scope for improvement in the effectiveness of VKAs by increasing the proportion of eligible patients who receive treatment and by increasing the time in therapeutic range for those who receive treatment.

Of the new anticoagulants being developed as possible replacements for VKAs (Table 4), dabigatran etexilate and rivaroxaban are the most advanced and have already been approved for use to prevent VTE after major orthopedic surgery. Phase III data are available for ximelagatran and idraparinux in $\mathrm{AF}$, but ximelagatran was withdrawn because of liver toxicity, and further development with idraparinux was halted because of increased bleeding. Phase III trials for dabigatran etexilate and rivaroxaban are due to be completed in 2009, apixaban in 2010, and DU-176b and idrabiotaparinux in 2011. If these agents are found to be effective and safe, then approval for clinical use can be expected to follow shortly thereafter.

\section{CLINICAL CHALLENGES IN A FUTURE ERA OF NEW ANTICOAGULANTS}

The possible approval of several new anticoagulants for long-term treatment of patients with $\mathrm{AF}$ who are at risk of stroke will bring a new set of challenges for physicians (Table 5). Although some of these agents are already approved for short term use in other clinical settings, 
Table 5 Challenges in the Clinical Adoption of New Anticoagulants

- No validated tests to measure anticoagulation effect

- No established therapeutic range

- No antidote for most agents

- Assessment of compliance more difficult than for vitamin $\mathrm{K}$ antagonists

- Potential for unknown long-term adverse effects

- Balancing cost against efficacy

- Lack of head-to-head studies comparing new agents

their long-term use in large numbers of patients with AF will raise questions concerning laboratory monitoring in selected clinical settings, reversal of anticoagulant effect, and long-term safety.

The new anticoagulants generally have a predictable anticoagulant response that allows for convenient, fixed-dose, and unmonitored treatment. However, there will be specific circumstances in which laboratory assessment of the anticoagulant effect will be important for clinical decision making. In the case of apparent treatment failure, assessment of adequacy of anticoagulant effect might help in the assessment of compliance with treatment and decision making about future antithrombotic treatment. There will also be instances where quantifying the anticoagulant effect may be important, such as patients with reduced renal or hepatic function, patients with extremities of body weight, and those receiving concomitant medications that may affect anticoagulant response. Likewise, in patients presenting with bleeding complications, assessment of the intensity of anticoagulation is likely to have management implications. Most of the new anticoagulants in advanced clinical development do not have a defined therapeutic range or established protocols for laboratory monitoring of anticoagulant effect, but these will need to be developed as new anticoagulants become available.

Of the new anticoagulants, only idrabiotaparinux and ATI-5923 have specific reversal agents. For the remainder of the new anticoagulants, there are no clinical data evaluating the effectiveness of coagulation factors or hemostatic agents such as recombinant factor VIIa to reverse their anticoagulant effect, although there is some animal data ${ }^{33}$ and anecdotal human experience on the use of such agents. For new anticoagulants with short half-lives, the issue of reversal is less important than for longer acting agents. However, in the setting of major bleeding or emergency surgery, acute reversal of anticoagulant effect will still be important. Finally, given the chronic nature of AF and the often indefinite duration of treatment, longterm safety evaluation of the new anticoagulants will be essential.

\section{REFERENCES}

1. Go AS, Hylek EM, Phillips KA, et al. Prevalence of diagnosed atrial fibrillation in adults: national implications for rhythm management and stroke prevention: the AnTicoagulation and Risk Factors in Atrial Fibrillation (ATRIA) Study. JAMA 2001;285(18):2370-2375

2. Miyasaka Y, Barnes ME, Gersh BJ, et al. Secular trends in incidence of atrial fibrillation in Olmsted County, Minnesota, 1980 to 2000, and implications on the projections for future prevalence. Circulation 2006;114(2):119-125

3. Risk factors for stroke and efficacy of antithrombotic therapy in atrial fibrillation. Analysis of pooled data from five randomized controlled trials. Arch Intern Med 1994;154(13):1449-1457

4. Wolf PA, Abbott RD, Kannel WB. Atrial fibrillation as an independent risk factor for stroke: the Framingham Study. Stroke 1991;22(8):983-988

5. Dulli DA, Stanko H, Levine RL. Atrial fibrillation is associated with severe acute ischemic stroke. Neuroepidemiology 2003;22(2):118-123

6. Lin HJ, Wolf PA, Kelly-Hayes M, et al. Stroke severity in atrial fibrillation. The Framingham Study. Stroke 1996;27(10): 1760-1764

7. Wolf PA, Mitchell JB, Baker CS, Kannel WB, D'Agostino RB. Impact of atrial fibrillation on mortality, stroke, and medical costs. Arch Intern Med 1998;158(3):229-234

8. Hart RG, Pearce LA, Aguilar MI. Meta-analysis: antithrombotic therapy to prevent stroke in patients who have nonvalvular atrial fibrillation. Ann Intern Med 2007;146(12): $857-867$

9. Lip GY, Edwards SJ. Stroke prevention with aspirin, warfarin and ximelagatran in patients with non-valvular atrial fibrillation: a systematic review and meta-analysis. Thromb Res 2006;118(3):321-333

10. Glazer NL, Dublin S, Smith NL, et al. Newly detected atrial fibrillation and compliance with antithrombotic guidelines. Arch Intern Med 2007;167(3):246-252

11. Hart RG, Benavente O, McBride R, Pearce LA. Antithrombotic therapy to prevent stroke in patients with atrial fibrillation: a meta-analysis. Ann Intern Med 1999;131(7): 492-501

12. Albers GW, Dalen JE, Laupacis A, Manning WJ, Petersen $\mathrm{P}$, Singer DE. Antithrombotic therapy in atrial fibrillation. Chest 2001;119(1, suppl):194S-206S

13. Go AS, Hylek EM, Borowsky LH, Phillips KA, Selby JV, Singer DE. Warfarin use among ambulatory patients with nonvalvular atrial fibrillation: the anticoagulation and risk factors in atrial fibrillation (ATRIA) study. Ann Intern Med 1999;131(12):927-934

14. Go AS, Hylek EM, Chang Y, et al. Anticoagulation therapy for stroke prevention in atrial fibrillation: how well do randomized trials translate into clinical practice? JAMA 2003;290(20):2685-2692

15. McCormick D, Gurwitz JH, Goldberg RJ, et al. Prevalence and quality of warfarin use for patients with atrial fibrillation in the long-term care setting. Arch Intern Med 2001; 161(20):2458-2463

16. Bradley BC, Perdue KS, Tisdel KA, Gilligan DM. Frequency of anticoagulation for atrial fibrillation and reasons for its nonuse at a Veterans Affairs medical center. Am J Cardiol 2000; 85(5):568-572

17. Bungard TJ, Ghali WA, Teo KK, McAlister FA, Tsuyuki RT. Why do patients with atrial fibrillation not receive warfarin? Arch Intern Med 2000;160(1):41-46 
18. Jones M, McEwan P, Morgan CL, Peters JR, Goodfellow J, Currie CJ. Evaluation of the pattern of treatment, level of anticoagulation control, and outcome of treatment with warfarin in patients with non-valvar atrial fibrillation: a record linkage study in a large British population. Heart 2005;91(4):472-477

19. Rose AJ, Ozonoff A, Henault LE, Hylek EM. Warfarin for atrial fibrillation in community-based practise. J Thromb Haemost 2008;6(10):1647-1654

20. Shalev V, Rogowski O, Shimron O, et al. The interval between prothrombin time tests and the quality of oral anticoagulants treatment in patients with chronic atrial fibrillation. Thromb Res 2007;120(2):201-206

21. Hylek EM, Go AS, Chang Y, et al. Effect of intensity of oral anticoagulation on stroke severity and mortality in atrial fibrillation. N Engl J Med 2003;349(11):1019-1026

22. White HD, Gruber M, Feyzi J, et al. Comparison of outcomes among patients randomized to warfarin therapy according to anticoagulant control: results from SPORTIF III and V. Arch Intern Med 2007;167(3):239-245

23. Wienen W, Stassen JM, Priepke H, Ries UJ, Hauel N. In-vitro profile and ex-vivo anticoagulant activity of the direct thrombin inhibitor dabigatran and its orally active prodrug, dabigatran etexilate. Thromb Haemost 2007;98(1):155-162

24. Stangier J, Rathgen K, Stähle H, Gansser D, Roth W. The pharmacokinetics, pharmacodynamics and tolerability of dabigatran etexilate, a new oral direct thrombin inhibitor, in healthy male subjects. Br J Clin Pharmacol 2007;64(3): 292-303

25. Stangier J. Clinical pharmacokinetics and pharmacodynamics of the oral direct thrombin inhibitor dabigatran etexilate. Clin Pharmacokinet 2008;47(5):285-295

26. Sanford M, Plosker GL. Dabigatran etexilate. Drugs 2008; 68(12):1699-1709

27. Eriksson BI, Dahl OE, Rosencher N, et al; RE-MODEL Study Group. Oral dabigatran etexilate vs. subcutaneous enoxaparin for the prevention of venous thromboembolism after total knee replacement: the RE-MODEL randomized trial. J Thromb Haemost 2007;5(11):2178-2185

28. Eriksson BI, Dahl OE, Rosencher N, et al; RE-NOVATE Study Group. Dabigatran etexilate versus enoxaparin for prevention of venous thromboembolism after total hip replacement: a randomised, double-blind, non-inferiority trial. Lancet 2007;370(9591):949-956

29. Ginsberg JS, Davidson BL, Comp PC, et al; RE-MOBILIZE Writing Committee. Oral thrombin inhibitor dabigatran etexilate vs North American enoxaparin regimen for prevention of venous thromboembolism after knee arthroplasty surgery. J Arthroplasty 2009;24(1):1-9

30. Ezekowitz MD, Reilly PA, Nehmiz G, et al. Dabigatran with or without concomitant aspirin compared with warfarin alone in patients with nonvalvular atrial fibrillation (PETRO Study). Am J Cardiol 2007;100(9):14191426

31. Kubitza D, Becka M, Wensing G, Voith B, Zuehlsdorf M. Safety, pharmacodynamics, and pharmacokinetics of BAY 59-7939—an oral, direct Factor Xa inhibitor-after multiple dosing in healthy male subjects. Eur J Clin Pharmacol 2005; 61(12):873-880

32. Weinz C, Schwartz T, Pleiss U. Metabolism and distribution of (14C) BAY 59-7939 - an oral, direct factor Xa inhibitorin rat, dog and human [abstract 196]. Drug Metab Rev 2004;36(suppl 1)
33. Eriksson BI, Quinlan DJ, Weitz JI. Comparative pharmacodynamics and pharmacokinetics of oral direct thrombin and factor xa inhibitors in development. Clin Pharmacokinet 2009;48(1):1-22

34. Kakkar AK, Brenner B, Dahl OE, et al; RECORD2 Investigators. Extended duration rivaroxaban versus shortterm enoxaparin for the prevention of venous thromboembolism after total hip arthroplasty: a double-blind, randomised controlled trial. Lancet 2008;372(9632):3139

35. Eriksson BI, Borris LC, Friedman RJ, et al; RECORD1 Study Group. Rivaroxaban versus enoxaparin for thromboprophylaxis after hip arthroplasty. N Engl J Med 2008; 358(26):2765-2775

36. Lassen MR, Ageno W, Borris LC, et al; RECORD3 Investigators. Rivaroxaban versus enoxaparin for thromboprophylaxis after total knee arthroplasty. N Engl J Med 2008; 358(26):2776-2786

37. Turpie A, Bauer K, Davidson B, et al. Comparison of 'Xarelto' - an oral, direct factor Xa inhibitor and subcutaneous enoxaparin for thromboprophylaxis after total knee replacement (RECORD4: a phase 3 study). Paper presented at: European Federation of National Associations of Orthopaedics and Traumatology annual meeting; May 29-June 1, 2008; Nice, France; Abstract F85

38. Frost $\mathrm{C}, \mathrm{Yu} \mathrm{Z}$, Nepal S. Apixaban, a direct factor $\mathrm{Xa}$ inhibitor: single-dose pharmacokinetics and pharmacodynamics of an intravenous formulation. Paper presented at: 37th American College of Chest Physicians annual meeting; September 14-16, 2008; Philadelphia, PA

39. Raghavan N, Frost CE, Yu Z, et al. Apixaban metabolism and pharmacokinetics after oral administration to humans. Drug Metab Dispos 2009;37(1):74-81

40. Lassen MR, Davidson BL, Gallus A, Pineo G, Ansell J, Deitchman D. The efficacy and safety of apixaban, an oral, direct factor $\mathrm{Xa}$ inhibitor, as thromboprophylaxis in patients following total knee replacement. J Thromb Haemost 2007; 5(12):2368-2375

41. Buller HR. Late breaking clinical trial: a dose finding study of the oral direct factor xa inhibitor apixaban in the treatment of patients with acute symptomatic deep vein thrombosis The Botticelli Investigators. J Thromb Haemost 2007; 5(suppl 2):Abstract S-003

42. Zafar MU, Vorchheimer DA, Gaztanaga J, et al. Antithrombotic effects of factor Xa inhibition with DU-176b: Phase-I study of an oral, direct factor Xa inhibitor using an ex-vivo flow chamber. Thromb Haemost 2007;98(4):883888

43. Walenga JM, Jeske WP, Fareed J. Short- and long-acting synthetic pentasaccharides as antithrombotic agents. Expert Opin Investig Drugs 2005;14(7):847-858

44. Herbert JM, Hérault JP, Bernat A, et al. Biochemical and pharmacological properties of SANORG 34006, a potent and long-acting synthetic pentasaccharide. Blood 1998;91(11): 4197-4205

45. Trellu M, Perez Y, Ortiz J, Cheng S, Paty I. Bioequipotency of idraparinux and biotinylated idraparinux after single dose in healthy subjects. [Abstract P-T-678]J Thromb Haemost 2007;5(suppl 1):Abstract P-T-678

46. Buller HR, Destors J, Gallus AS, Prins MH, Raskob GE. Idrabiotaparinux, a biotinylated long-acting anticoagulant, in the treatment of deep venous thrombosis (EQUINOX study): safety, efficacy, and reversibility by avidin. Paper 
presented at: American Society of Hematology; 2008; San Francisco, CA

47. Buller HR, Cohen AT, Davidson B, et al; van Gogh Investigators. Idraparinux versus standard therapy for venous thromboembolic disease. N Engl J Med 2007;357(11):10941104

48. Bousser MG, Bouthier J, Büller HR, et al; Amadeus Investigators. Comparison of idraparinux with vitamin
$\mathrm{K}$ antagonists for prevention of thromboembolism in patients with atrial fibrillation: a randomised, openlabel, non-inferiority trial. Lancet 2008;371(9609):315321

49. Ezekowitz MD, Milner P, Ellis D, et al. The utility of genotyping in the first evaluation of a novel vitamin $\mathrm{K}$ antagonist: ATI-5923. Circulation 2008; 118(Suppl 885): Abstract 4415 